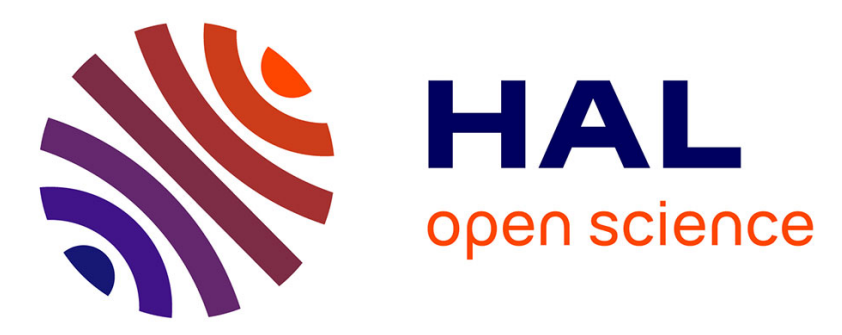

\title{
Metal valorization from the waste produced in the manufacturing of Co/Mo catalysts: leaching and selective precipitation
}

\author{
Mohammed F. Hamza, Jean-Claude Roux, Eric Guibal
}

\section{- To cite this version:}

Mohammed F. Hamza, Jean-Claude Roux, Eric Guibal. Metal valorization from the waste produced in the manufacturing of Co/Mo catalysts: leaching and selective precipitation. JOURNAL OF MATERIAL CYCLES AND WASTE MANAGEMENT, 2019, 21 (3), pp.525-538. 10.1007/s10163-0180811-9 . hal-02425053

\section{HAL Id: hal-02425053 \\ https://hal.science/hal-02425053}

Submitted on 4 Feb 2020

HAL is a multi-disciplinary open access archive for the deposit and dissemination of scientific research documents, whether they are published or not. The documents may come from teaching and research institutions in France or abroad, or from public or private research centers.
L'archive ouverte pluridisciplinaire HAL, est destinée au dépôt et à la diffusion de documents scientifiques de niveau recherche, publiés ou non, émanant des établissements d'enseignement et de recherche français ou étrangers, des laboratoires publics ou privés. 


\title{
Metal valorization from the waste produced in the manufacturing of Co/Mo catalysts: leaching and selective precipitation
}

\author{
Mohammed F. Hamza ${ }^{1,2} \cdot$ Jean-Claude Roux ${ }^{1} \cdot$ Eric Guibal $^{1}$
}

\begin{abstract}
Two different strategies have been designed for the acid and alkaline leaching steps of hydrodesulphurization catalysts. Tests have been performed on out-of-range catalysts issued from catalyst manufacturing process. Experimental conditions have been screened for these different processes considering the effects of concentration, temperature, solid/ liquid ratio, etc. The best conditions have been used for producing two leachates that were treated by precipitation for recovery of valuable met-als such as cobalt and molybdenum. Post-treatments have also been designed for the selective separation of Co from Mo: X-ray diffraction analyses on selective precipitates (as sulfide) confirm the purity of produced materials. Two flow sheets are proposed that allow selectively recovering more than $95 \%$ of the valuable metals.
\end{abstract}

Keywords Hydrodesulfurization catalyst $\cdot$ Co and Mo selective recovery $\cdot$ Alkaline leaching $\cdot$ Acidic leaching $\cdot$ Sulfide precipitation

\section{Introduction}

The development of processes for the recovery of valuable metals from WEEE (waste electric and electronic equipment), spent catalysts, fly ash, and low-grade ores became a strategic research field for the last decade due to the high demand for critical metals and the rarefaction of metal resources. Pyrometallurgy and hydrometallurgy are the main processes for valorization of these mineral resources; gravimetric and magnetic separations of grinded materials are the first steps for the enrichment and separation of inorganic solids, prior to calcining, roasting or smelting (for pyrometallurgy) $[1,2]$ or to leaching (for hydrometallurgy) [3-5]. Hydrometallurgy can be applied after pyrometallurgy has produced enriched solid concentrates for further separation.

Eric Guibal

Eric.Guibal@mines-ales.fr

C2MA, IMT Mines Ales, Univ. Montpellier, Alès, France

2 Nuclear Materials Authority, PO Box 530, El-Maadi, Cairo, Egypt
The leaching of spent catalysts from oil industry, waste electric, WEEEs, landfill deposits has retained a great attention for the last decades and an abundant amount of literature is available in this field [6-12]. Many techniques have been proposed using acidic leaching [3, 13-15], alkaline leaching $[16,17]$, chlorination process $[18,19]$ or bioleaching [20] for metal transfer from the solid waste or low-grade ore to the aqueous phase. The recovery of the valuable metals from leachates is frequently made complex by the presence of multiple metals, including elements like $\mathrm{Si}$ and $\mathrm{Al}$ that can strongly compete with valuable metals for recovery process, especially due to their very high concentration levels (these elements are the main constituents of the catalyst support or the ore). A wide range of processes can be used for metal recovery from precipitation [21-25] and solvent extraction [26] to binding on ion exchange or chelating resin (and similar materials like sorbents and biosorbents) [27-29]. The choice between the different strategies depends on the metal content in the solid, the presence of inert elements and/or poisoning compounds [5]. In the case of spent catalysts the poisoning of the catalyst surface with organic compounds, unburnt substances, carbon residues may cause a kind of inert effect that frequently requires preliminary calcination and/or oxidation of the solid with strong oxidizing agents.

In the industrial manufacturing of catalysts, the quality control of the products frequently leads to rejecting materials 
that are out of tolerance range in terms of morphology aspects (shape, size), mechanical stability, and active catalyst metal content. These materials may contain valuable metals at relatively high mass concentration; their metal content is also limiting the possibility to discharge these outof-range catalysts to the environment. In addition, in many countries, the regulations on waste management explicitly require recycling industrial products prior to their discharge into controlled deposits. The recovery of the metals from these materials is much less complex due to the relative purity of these supports (not contaminated with poisoning substances).

The objective of the present research consists of investigating the leaching of out-of-range hydrodesulfurization catalysts (mixed cobalt-molybdenum metals deposited on alumina/aluminosilicate support) before studying the selective separation of valuable metals ( $\mathrm{Co}$ and $\mathrm{Mo}$ ) from $\mathrm{Al}$ (and $\mathrm{Si}$ ). Acid and alkaline leachings are successively investigated to evaluate the best process for achieving the selective separation of the metals (in the proper leaching process but also in the integrated process). The effects of reagent type and concentration, the influence of contact time, temperature and solid/liquid (S/L) ratio are investigated. In a second step, the recovery of metals is carried out using $\mathrm{pH}$ control (metal hydroxide precipitation) and alternatively by sulfide precipitation, with the objective to be the most selective possible in the separation of valuable metals against $\mathrm{Al}$ and $\mathrm{Si}$, but also in the separation of Mo from Co metals. The leaching and recovery efficiencies are systematically evaluated by metal analysis in the aqueous phases, while the composition of products (pristine catalyst, treated material, and final metal precipitates) is evaluated by SEM-EDX analysis.

\section{Materials and methods}

\section{Materials and catalyst}

The hydrodesulfurization (HDS) catalyst used in this study is a material whose dimensions and/or metal contents were out of the tolerance ranges for industrial use. The raw material is characterized by a rod/slab-like shape (with lateral grooves) with $2 \mathrm{~mm}$ lateral dimension and 5-15 $\mathrm{mm}$ length. The stock of catalyst was coned and quartered (sample splitter) for preparing identical samples (Figure AM1, see Additional Material Section) [30]. The material was also tested as crushed material (using a ball mill Retsh Bioblock, Ilkirsh, France): the final size after sieving was 100-200 mesh $(75-150 \mu \mathrm{m})$. A new step of quartering was operated to prepare crushed identical samples that were processed for analysis and leaching.

Reagents of analytical grade were supplied by SigmaAldrich (Taufkirchen, Germany): $\mathrm{HCl}, \mathrm{H}_{2} \mathrm{SO}_{4}$, $\mathrm{HNO}_{3}$, oxalic acid, and by VWR-Prolabo (Fontenay-sous-Bois, France): sodium carbonate, sodium bicarbonate, sodium sulfide, and hydrogen peroxide.

\section{Characterization of materials}

The structure of the catalyst was characterized by X-ray diffraction analysis using a XRD Bruker D8 Advance diffractometer in a $\theta-\theta$ configuration; the $\mathrm{Cu} \mathrm{K} \alpha$ radiation (1.54 $\AA$ ) was used with a fixed divergence slit size of $0.6^{\circ}$ and a rotating sample stage. The samples were scanned between $5^{\circ}$ and $180^{\circ}$ with a lynx-eye- 1 detector. The qualitative analysis was performed with the X'Pert High Score Plus software (v. 2.1), with the knife edge off.

The textural properties of the catalyst were determined using a surface area and porosity analyzer (Micromeritics TriStar II Plus, Micromeritics Instrument Group, Norcross, GA, USA). The sample $(1.05 \mathrm{~g})$ was degassed at $60{ }^{\circ} \mathrm{C}$ for $48 \mathrm{~h}$ prior to processing the $\mathrm{N}_{2}$ adsorption/desorption cycle.

The elemental composition of the catalyst was determined by acid attack using an aqua regia $\left(1: 3 \mathrm{HNO}_{3} / \mathrm{HCl}\right.$ mixture $)$ digestion method [31]: $1 \mathrm{~g}$ of crushed catalyst was mixed with aqua reggia at $120{ }^{\circ} \mathrm{C}$ for $40-45 \mathrm{~min}$, the final volume of solution after sample digestion was $27 \mathrm{~mL}$. After cooling, the solution was double-filtrated on $0.45 \mu \mathrm{m}$ pore-size membrane filter and then diluted with Milli-Q water for further analysis of Mo, Co and $\mathrm{Al}$ using an inductively coupled plasma atomic emission spectrometer (ICP-AES, Activa M Horiba Jobin-Yvon, Longjumeau, France).

The materials were also characterized by SEM-EDX analysis using a Quanta FEG 200 (FEI France, Thermo Fisher Scientific, Merignac, France), equipped with an Oxford Inca 350 energy dispersive $\mathrm{X}$-ray micro-analyzer (Oxford instruments France, Saclay, France). The SEM-EDX analysis was performed on the raw catalyst but also on the intermediary products (after leaching operations) and on final products for evaluating the efficiency of leaching, precipitation and the purity of elaborated products.

\section{Procedures for metal leaching}

For the testing of metal leaching, different methods (acid leaching and alkaline leaching) were used. With organic and inorganic acids, the catalyst sample ( $\mathrm{m}, 5 \mathrm{~g}$ ) was introduced in a four-neck glass flask equipped with a condenser, an agitator and a thermometer. Different parameters have been tested such as: particle size (grain, raw rod/slag), acid concentration, solid/liquid ratio $\left(S / L, \mathrm{~g} \mathrm{~L}^{-1}\right)$, contact time and temperature. For alkaline leaching, the sodium carbonate/sodium bicarbonate mass ratio was varied as well as the concentration of the alkaline mixture (w/w, ratio with total amount of carbonate/bicarbonate mixture, for example, ratio $1: 2$ for a $10 \%$ concentration: $3.33 \mathrm{~g}$ of $\mathrm{Na}_{2} \mathrm{CO}_{3}+6.67 \mathrm{~g}$ of 
$\mathrm{NaHCO}_{3}$ for $100 \mathrm{~mL}$ of water), the $S / L$ ratio, the contact time and the temperature. It is noteworthy that for the study of $S / L$ ratio, the wetting of dry catalyst represented a volume of leaching agent almost equivalent in mass to the amount of catalyst, and the $S / L$ ratio will actually correspond to the ratio of solid to residual volume of leachate. As a consequence, the $S /$ leachate volume $=1 / n$ corresponds to the experimental S/leaching agent $=1 /(n+1)$.

Leachate samples were collected in the supernatant of the liquor of acid/alkaline leaching in the reactor. After filtration through $0.45 \mu \mathrm{m}$ pore-size membrane filter metal concentrations were obtained by ICP-AES. The leaching efficiency was calculated by the mass balance equation.

\section{Procedures for precipitation}

The acidic leachates were treated by precipitation using sodium sulfide (40\%), sodium hydroxide (5 M), while alkaline leachates were first neutralized using concentrated sulfuric acid then precipitated using sodium sulfide $(40 \%$, $\mathrm{w} / \mathrm{w})$. A fixed volume of leachate was $\mathrm{pH}$ controlled using the precipitating agent. The mixture was maintained under agitation in a jar test at the rotating speed of $200 \mathrm{rpm}$ for $1 \mathrm{~h}$. The metal concentration in the solution after filtration was analyzed using ICP-AES. The mass balance equation was used for calculating the precipitation efficiency and the recovery efficiency of the metal from the catalyst.

These characterizations were completed by SEM-EDX analysis for evaluating the purity of precipitates and the presence of residual amounts of metals in the catalyst at the different stages of the recovery processes.

\section{Repeatability issues}

Preliminary tests were performed on $5 \mathrm{~g}$ amounts of catalysts for evaluating the general impact of individual parameters and pre-selecting experimental conditions. In a second step of the study, the amounts of processed catalysts were increased to 50 and $100 \mathrm{~g}$. The repeatability was evaluated. Tables AM1 and AM2 (see Additional Material Section) show a summary of the comparison of data considering the EDX analysis of precipitates obtained in the different compartments for both acidic and alkaline leaching processes. Tables AM3 and AM4 report the metal concentrations, leaching and precipitation efficiencies at different stages of the two leaching processes. These data confirm that the extraction and separation performances are reproducible. In most cases, the variation did not exceed 3-5\% (for target metal subject to specific treatment). The selected optimum conditions have been used for treating an amount of $500 \mathrm{~g}$ of catalyst and preparing a sufficient amount of leachates for extensive study of selective metal precipitation and separation.

\section{Results and discussion}

\section{Characterization of catalysts}

The metal contents in the catalyst, as determined by aqua regia digestion, are $1.79,8.51$ and $27.45 \%$ for $\mathrm{Co}$, Mo and $\mathrm{Al}$, respectively (Table 1 ). These values are consistent with those found using SEM-EDX (Figure AM2a, see Additional Material Section): $1.68 \%$ for Co, $8.12 \%$ for Mo, $23.34 \%$ for Al, and 8.08 for $\mathrm{Si}$. As a comparison, the fraction of these elements in the solid was also determined by concentrated nitric acid and hydrochloric acid treatments: the contents are consistent for $\mathrm{Co}$ and $\mathrm{Al}$ but slightly underestimated for Mo in the case of nitric acid.

Figure AM2b shows the XRD diffraction pattern of the catalyst. This diffractogram is poorly resolved. However, the most significant bands representative of ill crystallized alumina can be identified (with PDF reference: 00-0040458). The presence of Si element (at a mass percentage of $8.08 \%$, or $5.73 \%$ atomic percentage) shows that the support may also contain silicate or aluminosilicate. This could explain the poor resolution of X-ray diffraction pattern.

Textural analysis (not shown) allowed determining the principal characteristics of the catalyst material: BET surface area close to $245 \mathrm{~m}^{2} \mathrm{~g}^{-1}$, the pore volume close to $0.4 \mathrm{~cm}^{3} \mathrm{~g}^{-1}$ and the pore size close to 65 Á. This confirms the high porosity of the catalyst and may explain the relatively facile access of the metal deposits to the leaching solutions.

The Co-Mo catalysts supported on alumina are usually prepared by successive impregnation steps of the alumina support with metal solutions in different orders of impregnation. In most cases, the cobalt is deposited on alumina support before impregnating the Al-Co material with molybdenum: the Co exists as a thin layer between the Mo layer and the Al support [32]. In the pristine HDS catalyst molybdenum is under the oxidized form $(\mathrm{Mo}(\mathrm{VI}))$ while after sulfidation (spent catalyst) the metal can be partially reduced [32].

Table 1 Metal content $(\%, w / w)$ in the catalyst (concentrated acid treatment, digestion with aqua regia, $1: 3 \mathrm{HNO}_{3} / \mathrm{HCl}$ solution, and EDX analysis on the solid) (solid: $1 \mathrm{~g}$; final volume: $27 \mathrm{~mL}$; contact time: $40-45 \mathrm{~min}$; temperature: $120^{\circ} \mathrm{C}$ )

\begin{tabular}{lllll}
\hline Metal & $\mathrm{HNO}_{3}$ & $\mathrm{HCl}$ & Aqua regia & EDX analysis \\
\hline $\mathrm{Al}$ & 25.83 & 25.22 & 27.45 & 23.34 \\
$\mathrm{Mo}$ & 5.41 & 7.50 & 8.51 & 8.12 \\
$\mathrm{Co}$ & 1.68 & 1.62 & 1.79 & 1.68 \\
$\mathrm{Si}$ & n.d & n.d & n.d & 8.08 \\
\hline
\end{tabular}

$n d$ not determined 


\section{Metal leaching}

\section{Acid leaching}

Effect of the type of acid Table 2 reports the effect of the acid used on the leaching of $\mathrm{Al}, \mathrm{Mo}$ and Co. The tests were performed on both raw catalyst $(\mathrm{R})$ and crushed catalyst (C) at two levels of concentration of the acid (50 and $100 \mathrm{~g}$ $\left.\mathrm{L}^{-1}\right)$. The cross-variation show consistent trends: the leaching efficiency is slightly increased with increasing acid concentration, regardless of the metal. The acid does not affect Al leaching contrary to Mo and Co that are more efficiently leached by sulfuric acid than nitric or hydrochloric acid (which are equally recovered by these two acids). In the case of acidic leaching of spent hydrodesulfurization catalysts, Valverde et al. [33] reported the formation of several species depending on the acid used (sulfuric acid vs. hydrochloric acid):

$$
\mathrm{CoO}+\mathrm{H}_{2} \mathrm{SO}_{4} \rightarrow \mathrm{CoSO}_{4}+\mathrm{H}_{2} \mathrm{O}
$$

$$
\begin{aligned}
& \mathrm{Al}_{2} \mathrm{O}_{3}+3 \mathrm{H}_{2} \mathrm{SO}_{4} \rightarrow \mathrm{Al}_{2}\left(\mathrm{SO}_{4}\right)_{3}+3 \mathrm{H}_{2} \mathrm{O} \\
& \mathrm{MoO}_{3}+\mathrm{H}_{2} \mathrm{SO}_{4} \rightarrow \mathrm{MoO}_{2} \mathrm{SO}_{4}+\mathrm{H}_{2} \mathrm{O} \\
& \mathrm{CoO}+2 \mathrm{HCl} \rightarrow \mathrm{CoCl}_{2}+\mathrm{H}_{2} \mathrm{O} \\
& \mathrm{Al}_{2} \mathrm{O}_{3}+6 \mathrm{HCl} \rightarrow 2 \mathrm{AlCl}_{3}+3 \mathrm{H}_{2} \mathrm{O} \\
& \mathrm{MoO}_{3}+2 \mathrm{HCl} \rightarrow \mathrm{MoO}_{2} \mathrm{Cl}_{2}+\mathrm{H}_{2} \mathrm{O} .
\end{aligned}
$$

Lai et al. [12] concluded that a mixture of acids (2:1:1 $\mathrm{HNO}_{3} / \mathrm{H}_{2} \mathrm{SO}_{4} / \mathrm{HCl}$ ) is optimal for the recovery of $\mathrm{Ni}$, Mo and $\mathrm{V}$ from spent HDS catalyst (with limited selectivity in the leaching). They commented that the introduction of concentrated $\mathrm{HCl}$ contributed to the formation of metal-chloride complexes that enhance metal leaching. The oxidation state of the metal in the catalyst may affect the reaction (and metal species present in the leachate); in the case of partially preoxidized HDs catalyst, Kim et al. [11] reported the additional reaction:

$$
\mathrm{Co}_{2} \mathrm{O}_{3}+3 \mathrm{H}_{2} \mathrm{SO}_{4} \rightarrow \mathrm{Co}_{2}\left(\mathrm{SO}_{4}\right)_{3}+3 \mathrm{H}_{2} \mathrm{O}
$$

In most cases, the size of the material hardly changes the leaching efficiency (by a few \%) except in the case of Co removal using sulfuric acid where decreasing the particle size significantly improves by $11 \%$ the efficiency of metal leaching (this means a relative increase of about $50 \%$ compared with raw material). The limited effect of particle size means that the metal sites are highly accessible: the porosity of the catalyst may explain this result (see above).

The efficiency in metal recovery is of the same order for $\mathrm{Mo}$ and $\mathrm{Co}$ and much higher than for $\mathrm{Al}$. Al is the core and support of the catalyst (alumina and aluminosilicate): the proportion of aluminum is then much higher than that of the catalytic metals. This may explain the lower release of this metal under selected experimental conditions. The poor leaching of $\mathrm{Al}$ is interesting for the objective of separating valuable metals from the structural core of the catalyst. In addition, the catalytic metals are supposed to be deposited as a thin layer on the porous surface of the support; this means that metal sites can be well-accessed and better dissolved by the acid than the metal from core support.

These preliminary results show that sulfuric acid is the most efficient leaching agent for the treatment of these $\mathrm{Co} /$ Mo catalysts. Alternative acidic treatments have been tested for the recovery of metals from ores and catalysts or spent materials using organic acids [3, 34], including oxalic acid [35]. Some tests were carried out for the recovery of $\mathrm{Al}$, Co and Mo from the catalyst material using oxalic acid at the concentration of $50 \mathrm{~g} \mathrm{~L}^{-1}$; the leaching efficiency remained very low: $1.46-1.63 \%$ for $\mathrm{Al}, 1.55-2.62 \%$ for Mo and 1.30-2.59\% for Co in raw and crushed catalysts. The efficiency of this alternative leaching agent is strongly increased using a strong oxidative agent: hydrogen peroxide has been successfully used for this purpose [6, 9, 36]. A complementary test was then performed using a higher concentration of oxalic acid (i.e., $100 \mathrm{~g} \mathrm{~L}^{-1}$ ) in the presence of hydrogen peroxide (at the concentration of $0.2 \mathrm{M}$, and with a 1:25 $S / L$ ratio). The leaching efficiency was strongly increased: $37.25 \%$ for $\mathrm{Al}, 28.52 \%$ for Co and up to $99.98 \%$ for Mo. This means that a huge amount of leaching agent is necessary for reaching the complete recovery of molybdenum, while significant amounts of $\mathrm{Al}$ and Co are simultaneously leached making complex the separation of the metals
Table 2 Effect of acid type (sulfuric acid, hydrochloric acid and nitric acid) and strength

\begin{tabular}{|c|c|c|c|c|c|c|c|}
\hline \multirow[t]{2}{*}{ Metal } & \multirow[t]{2}{*}{ Sample } & \multicolumn{2}{|c|}{ Sulfuric acid } & \multicolumn{2}{|c|}{ Hydrochloric acid } & \multicolumn{2}{|c|}{ Nitric acid } \\
\hline & & $50 \mathrm{~g} \mathrm{~L}^{-1}$ & $100 \mathrm{~g} \mathrm{~L}^{-1}$ & $50 \mathrm{~g} \mathrm{~L}^{-1}$ & $100 \mathrm{~g} \mathrm{~L}^{-1}$ & $50 \mathrm{~g} \mathrm{~L}^{-1}$ & $100 \mathrm{~g} \mathrm{~L}^{-1}$ \\
\hline \multirow[t]{2}{*}{$\mathrm{Al}$} & $\mathrm{R}$ & 4.98 & 5.50 & 4.70 & 5.02 & 4.43 & 4.73 \\
\hline & $\mathrm{C}$ & 4.06 & 7.27 & 4.71 & 5.08 & 5.15 & 5.36 \\
\hline \multirow[t]{2}{*}{ Mo } & $\mathrm{R}$ & 25.95 & 26.74 & 17.56 & 21.96 & 16.54 & 18.11 \\
\hline & $\mathrm{C}$ & 27.94 & 30.55 & 13.79 & 15.56 & 17.09 & 18.33 \\
\hline \multirow[t]{2}{*}{$\mathrm{Co}$} & $\mathrm{R}$ & 19.39 & 24.61 & 19.50 & 21.44 & 18.26 & 21.97 \\
\hline & $\mathrm{C}$ & 31.06 & 35.48 & 17.42 & 19.81 & 19.25 & 20.49 \\
\hline
\end{tabular}
$\left(50 \mathrm{~g} \mathrm{~L}^{-1}\right.$ or $\left.100 \mathrm{~g} \mathrm{~L}^{-1}\right)$ on the efficiency of metal leaching (\%) from raw material (R) and crushed (C) samples (Solid: $5 \mathrm{~g}$; Acid volume: $5.2 \mathrm{~mL}$; agitation time: $2 \mathrm{~h}$; $\mathrm{T}: 23 \pm 2{ }^{\circ} \mathrm{C}$ ) 
Table 3 Effect of sulfuric acid concentration $\left(\mathrm{g} \mathrm{L}^{-1}\right)$ on the efficiency of metal leaching from raw (R) and crushed (c) materials (Solid: $5 \mathrm{~g}$; Acid volume: $5.2 \mathrm{~mL}$; agitation time: $\left.2 \mathrm{~h} ; \mathrm{T}: 23 \pm 2{ }^{\circ} \mathrm{C}\right)$

\begin{tabular}{llllllllll}
\hline Metal & Sample & \multicolumn{7}{l}{ Sulfuric acid concentration $\left(\mathrm{g} \mathrm{L}^{-1}\right)$} \\
\cline { 3 - 9 } & & 50 & 100 & 150 & 200 & 250 & 300 & 400 & 500 \\
\hline Al & $\mathrm{R}$ & 5.21 & 2.11 & 8.59 & 10.13 & 11.57 & 11.61 & 12.97 & 13.81 \\
& $\mathrm{C}$ & 3.58 & 6.86 & 10.21 & 10.18 & 10.85 & 15.03 & 15.18 & 15.25 \\
Mo & $\mathrm{R}$ & 25.95 & 26.74 & 33.20 & 31.77 & 35.53 & 37.11 & 38.64 & 38.53 \\
& $\mathrm{C}$ & 27.94 & 30.55 & 29.05 & 28.11 & 31.44 & 38.11 & 39.09 & 38.99 \\
$\mathrm{No}$ & $\mathrm{R}$ & 19.39 & 24.61 & 36.71 & 36.92 & 39.72 & 40.31 & 40.42 & 42.68 \\
& $\mathrm{C}$ & 31.06 & 35.48 & 39.38 & 31.31 & 31.66 & 41.45 & 39.02 & 36.93 \\
\hline
\end{tabular}

in the next step of the process for metal recovery (i.e., precipitation): the precipitation of huge amounts of aluminum will probably co-precipitate substantial amounts of valuable metals. Beside the consumption of large quantities of oxalic acid (2.5 kg per kg of catalyst) and the dilution of the metals (due to the $S / L$ ratio of 1:25), it is a non-selective leaching that makes this process not really competitive, despite the complete recovery of molybdenum. For these reasons, the study was focused on sulfuric acid because of the relatively good leaching performance and the less expensive cost of this reagent.

Effect of $\mathrm{H}_{2} \mathrm{SO}_{4}$ concentration The influence of sulfuric acid concentration on the leaching efficiency is reported on Table 3. As expected, increasing acid concentration enhances metal recovery. However, the table clearly shows that $\mathrm{Al}$ recovery increases with acid concentration while for Co and Mo the leaching yield tends to stabilize when the concentration of sulfuric acid reaches $250-300 \mathrm{~g} \mathrm{~L}^{-1}$ : the benefits of increasing acid concentration on metal recovery is almost negligible and uneconomic. In addition, an excessive amount of acid will require using higher concentrations or volumes of alkaline solutions for further metal precipitation in the next step of the recovery process. Crushing the catalyst has a limited effect on leaching yield except for Co recovery at low sulfuric acid concentration: milling the catalyst hardly affects the equilibrium performance and it is expected that the main effect of material size is associated to leaching kinetic, although the porosity of this material probably minimizes this effect. An acidic concentration of $300 \mathrm{~g} \mathrm{~L}^{-1}$ is selected for further studies: the leaching efficiencies reach $11.6-15.0,37.1-38.1$, and $40.3-41.4 \%$ for $\mathrm{Al}$, Mo and Co, respectively.

Effect of $S / L$ ratio The $S / L$ ratio is an important criterion that may influence both the efficiency of leaching but also the metal concentration in the leachate. Increasing the volume of leaching solution usually improves the yield of dissolution but at the expense of a dilution of metal ion in the final solution. The optimization of the process should then take into account the efficiency and the dilution effect. Table 4 summarizes the results obtained varying the volumes of sul-
Table 4 Effect of solid/liquid ratio $(S / L)\left(\mathrm{g} \mathrm{L}^{-1}\right)$ on the efficiency of metal leaching with sulfuric acid $\left(300 \mathrm{~g} \mathrm{~L}^{-1}\right.$ solution) from crushed material (Solid: $5 \mathrm{~g}$; Acid volume: $5.2-25.2 \mathrm{~mL}$; agitation time: $2 \mathrm{~h}$; T: $\left.23 \pm 2{ }^{\circ} \mathrm{C}\right)$

\begin{tabular}{llllll}
\hline Metal & \multicolumn{4}{l}{$\begin{array}{l}\text { Acid volume }(\mathrm{mL}) \\
\text { S/L ratio }(1: \mathrm{N})\end{array}$} \\
\cline { 2 - 6 } & 5.2 & 10.2 & 15.2 & 20.2 & 25.2 \\
& $1: 1$ & $1: 2$ & $1: 3$ & $1: 4$ & $1: 5$ \\
\hline Al & 15.03 & 16.21 & 19.16 & 24.03 & 27.11 \\
Mo & 38.11 & 45.60 & 51.62 & 62.49 & 71.92 \\
Co & 41.45 & 44.72 & 50.20 & 59.31 & 67.72 \\
\hline
\end{tabular}

Table 5 Effect of contact time (h) on the efficiency of metal leaching with sulfuric acid ( $300 \mathrm{~g} \mathrm{~L}^{-1}$ solution) from crushed material (Solid: $5 \mathrm{~g}$; Acid volume: $20.2 \mathrm{~mL}$; $\mathrm{T}: 23 \pm 2{ }^{\circ} \mathrm{C}$ )

\begin{tabular}{llllll}
\hline Metal & \multicolumn{5}{l}{ Agitation time (h) } \\
\cline { 2 - 6 } & 2 & 3 & 4 & 5 & 6 \\
\hline Al & 24.03 & 26.39 & 37.25 & 37.40 & 41.60 \\
Mo & 62.49 & 81.03 & 90.43 & 92.20 & 98.55 \\
Co & 59.31 & 75.52 & 83.43 & 86.44 & 90.48 \\
\hline
\end{tabular}

furic acid $\left(300 \mathrm{~g} \mathrm{~L}^{-1}\right)$ used for the treatment of $5 \mathrm{~g}$ of catalyst. Dissolution yield continuously increases with the volume of acid for the three metals. However, when the volume exceeds $15 \mathrm{~mL}$, leaching efficiency tends to stabilize around $24 \%$ for $\mathrm{Al}, 62.5 \%$ for Mo and $59.3 \%$ for Co. The concentrations of the metals in the leachates approach $15 \mathrm{~g} \mathrm{Al} \mathrm{L}^{-1}$, $10.8 \mathrm{~g} \mathrm{Mo} \mathrm{L}^{-1}$ and $2.4 \mathrm{~g} \mathrm{Co} \mathrm{L}^{-1}$ when using $S / L$ ratio of 1:4. Above $S / L=1: 4$, the concentration in the leachate tends to decrease while dissolution is only slightly increased. A good compromise between metal concentrations in the leachate and desorption efficiency is obtained setting $S / L$ ratio to $1: 4$, this value was selected for investigating the effect of leaching time.

Effect of leaching time Maintaining the suspension in agitation for a longer time obviously allows increasing the leaching of metal ions (Table 5). After $6 \mathrm{~h}$ of agitation, $\mathrm{Al}$ recov- 
ery reaches $41.6 \%$, while for Mo and Co the leaching yields 98.5 and $90.5 \%$, respectively. Increasing the contact time has a main drawback on the practical point of view since it decreases the volumetric flux of treatment and/or increases the dimension of the treatment unit. The potential advantage of increasing the contact time should be measured taking into account the flux of treatment of the solid. Actually, the increase in contact time only allows slightly increasing the efficiency of leaching. With a contact time of $4 \mathrm{~h}$ the leaching efficiencies reach up to $37.2,90.4$ and $83.4 \%$ for $\mathrm{Al}, \mathrm{Mo}$ and Co, respectively. This compromise was selected for optimizing the temperature effect.

The effect of contact time on the leaching efficiency was modeled using the shrinking core model (SCM) with different control modes (i.e., film diffusion, particle layer diffusion control, and reaction rate) [37]. Table AM5 (see Additional Material Section, for data exploitation and reminder on kinetic equations) reports the kinetic parameters (rate coefficients) and the correlation parameters (ordinate intercept in the linearization of model equations, and determination coefficient, $R^{2}$ ). The best correlation was obtained with the SCM associated to particle layer diffusion control (highest relative $R^{2}$, and lowest ordinate intercept), which plays the major role in the kinetic control. However, the fits were not perfect and the leaching kinetic is probably controlled by a combination of different mechanisms. A more sophisticated model could be used [37], but it would require extending the number of experimental data. Another way to confirm this analysis would consist of testing the effect of particle size on the kinetic profile: crushing the catalyst slabs did not change the leaching yield but the kinetics were not compared for raw and crushed catalyst. It is noteworthy that in the acid leaching process the rate coefficients for the three metals were ranked according: Mo $\left(0.122 \mathrm{~h}^{-1}\right)>\mathrm{Co}\left(0.078 \mathrm{~h}^{-1}\right)>>\mathrm{Al}$ $\left(0.011 \mathrm{~h}^{-1}\right)$, while the equilibrium values were of the same order of magnitude for Mo and Co leaching.

Effect of temperature Table 6 compares the leaching efficiencies at three temperatures 25,50 and $100{ }^{\circ} \mathrm{C}$. The yield of metal removal drastically increases between $25{ }^{\circ} \mathrm{C}$ and $50{ }^{\circ} \mathrm{C}$ up to $65.6 \%$ for $\mathrm{Al}, 99.9 \%$ for Mo and $98.8 \%$ for Co. Increasing again the temperature to $100{ }^{\circ} \mathrm{C}$ is counterproductive: the marginal increase in Mo and Co recovery (which are complete) are accompanied by the simultaneous complete recovery of $\mathrm{Al}$. The leachates at $100{ }^{\circ} \mathrm{C}$ will then

Table 6 Effect of temperature $\left({ }^{\circ} \mathrm{C}\right)$ on the efficiency of metal leaching with sulfuric acid ( $300 \mathrm{~g} \mathrm{~L}^{-1}$ solution) from crushed material (Solid: $5 \mathrm{~g}$; Acid volume: $20.2 .2 \mathrm{~mL}$; agitation time: $4 \mathrm{~h}$ ) contain huge amounts of aluminum that will make more complex the selective separation of Mo and Co from $\mathrm{Al}$ without being justified by a beneficial recovery of valuable metals. It seems that a temperature close to $50{ }^{\circ} \mathrm{C}$ will be sufficient for reaching the efficient recovery of target metals without overloading the composition of the leachates with $\mathrm{Al}$, in the perspective of selective precipitation posttreatment.

To verify the reproducibility of the experiments and to also evaluate the impact of temperature on Co and Mo leaching kinetics, additional kinetic experiments were performed at $25{ }^{\circ} \mathrm{C}, 50{ }^{\circ} \mathrm{C}$ and $100{ }^{\circ} \mathrm{C}$ (Fig. 1). As the temperature increases the required contact time decreases and $4 \mathrm{~h}$ are sufficient in most cases for removing more than $90 \%$ of the total amount of metal that can be leached. Molybdenum is slightly faster released than cobalt. This is confirmed by Table AM6 (see Additional Material Section) that reports the modeling of kinetic profiles with the FDC, PLDC and
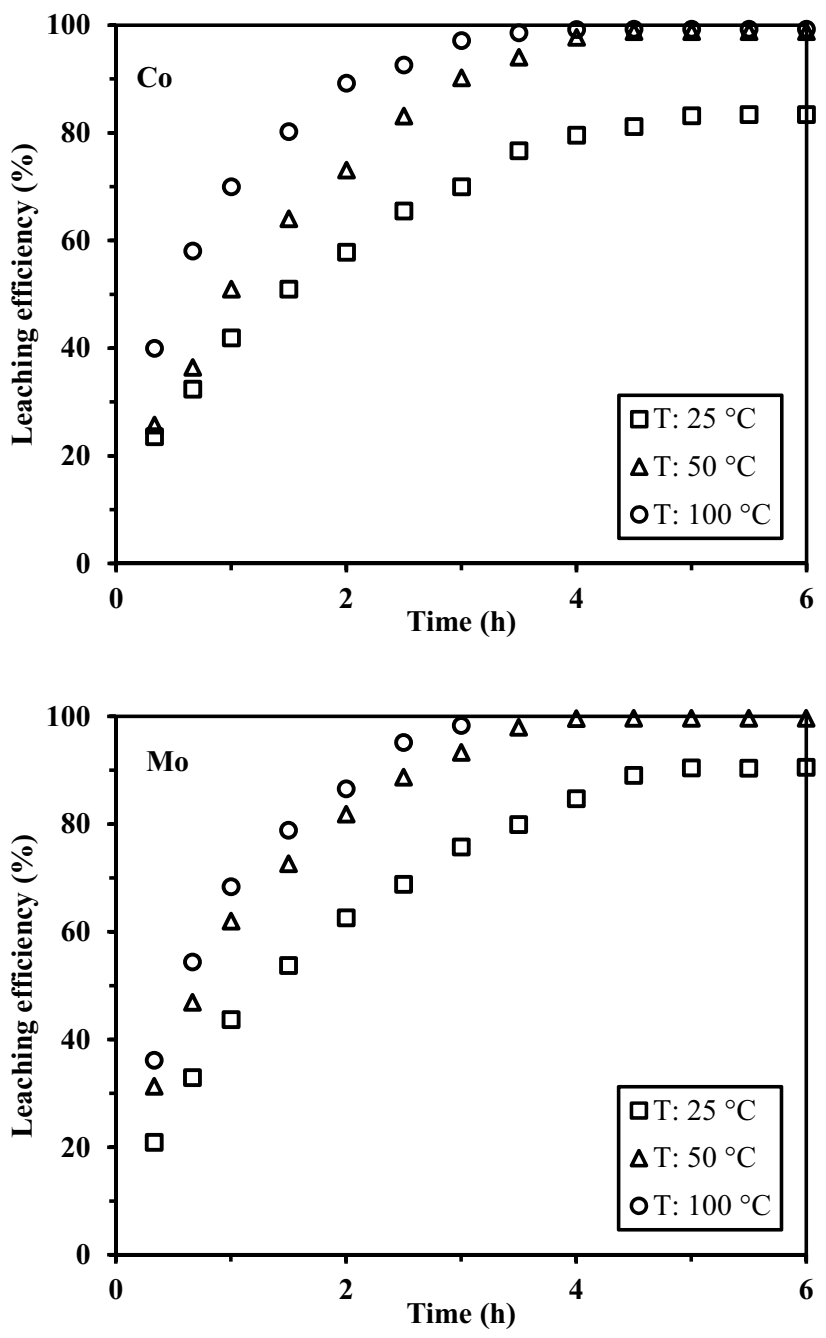

Fig. 1 Kinetics of $\mathrm{Co}$ and Mo acid leaching at different temperatures ( $300 \mathrm{~g} \mathrm{~L}^{-1} \mathrm{H}_{2} \mathrm{SO}_{4}$, Solid: $5 \mathrm{~g}$; Acid volume: $15.2 \mathrm{~mL}$ ) 
RC modes of the SCM model. Again, the FDC model failed to fit experimental profiles and the leaching curves are best fitted by the SCM-PLDC and the SCM-RC equations. The rate coefficients for PLDC and $\mathrm{RC}\left(\mathrm{k}_{\mathrm{i}}, \mathrm{h}\right)$ have been used for calculating the activation energy $\left(E_{\mathrm{a}}, \mathrm{kJ} \mathrm{mol}^{-1}\right)$ for the acid leaching of Co and Mo \{Tanda, $2018 \# 2630\}$ :

$k_{\mathrm{i}}=A \mathrm{e}^{-E_{\mathrm{a}} R / T}$,

where $A$ is a frequency factor, $T$ the absolute temperature $(K)$ and $R$ the universal gas constant $\left(\mathrm{J} \mathrm{mol}^{-1} \mathrm{~K}^{-1}\right)$.

The activation energies (average values calculated using the rate coefficients of both SCM-PLDC and SCM-RC) are close to $12.3( \pm 0.12)$ and $10.7( \pm 0.21) \mathrm{kJ} \mathrm{mol}^{-1}$ for $\mathrm{Co}$ and Mo, respectively (Figure AM3, see Additional Material Section). This confirms that Mo can be slightly more readily leached from the catalyst than Co.

\section{Alkaline leaching}

Acid leaching can be well-controlled and maintained at a lower cost, but the process generates leach liquor with significant concentrations of aluminum, which complicates downstream processing $[38,39]$. Alkaline leaching may be an alternative or complementary leaching process making profit of the differences in the chemistry of the target metals. Indeed, alkali carbonates (sodium or less commonly ammonium) are used for selective leaching of some elements that form stable soluble carbonate complex. Alkali carbonate leaching has several important advantages over acid leaching like its selectivity: comparatively pure solutions are readily obtained beside its non-corrosive nature [40]. Also, the consumption of the reagent by the ore is low and some elements can be readily recovered from the leach liquors. Finally, the carbonate solutions can be readily regenerated for further recycling of the leaching agent [41]. However, there are some limitations to the use of carbonate leaching due to its mild nature: some minerals are not solubilized by carbonate leach solutions. Moreover, it requires fairly fine grinding of the ore to obtain reasonable reaction rates [42]. Alternatively, carbonate leaching could be performed under relatively high pressure and temperature in suitable autoclaves [43]. Generally, sodium chlorate is used in carbonate leaching circuit $[30,44]$. Sodium hydroxide resulting from the reaction may contribute to increase the $\mathrm{pH}$ of the solution $\mathrm{pH}$, which, in turn, causes the precipitation of some elements. Therefore, to prevent an excessive rise of the $\mathrm{pH}$ (and unwanted metal re-precipitation), sodium bicarbonate is frequently used to the reactive media.

Effect of $\mathrm{Na}_{2} \mathrm{CO}_{3} / \mathrm{NaHCO}_{3}$ ratio Molar ratio between carbonate and bicarbonate was varied by increasing the amount of bicarbonate with fixed concentration of carbonate (Table 7). The recovery of aluminum and cobalt is negligible and
Table 7 Effect of $\mathrm{Na}_{2} \mathrm{CO}_{3}$ / $\mathrm{NaHCO}_{3}$ ratio on the efficiency of metal leaching from crushed material (Solid: $5 \mathrm{~g}$; alkaline concentration: $10 \%(\mathrm{w} / \mathrm{w})$; alkaline solution volume:

$5.3 \mathrm{~mL}$; agitation time: $2 \mathrm{~h}$; T: $\left.23 \pm 2{ }^{\circ} \mathrm{C}\right)$

\begin{tabular}{llll}
\hline Metal & \multicolumn{3}{l}{$\mathrm{Na}_{2} \mathrm{CO}_{3} / \mathrm{NaHCO}_{3}$} \\
\cline { 2 - 4 } & $1: 1$ & $1: 2$ & $1: 3$ \\
\hline $\mathrm{Al}$ & 0.09 & 0.12 & 0.10 \\
Mo & 18.47 & 21.53 & 20.15 \\
Co & 0.01 & 0 & 0 \\
\hline
\end{tabular}

Table 8 Effect of solid/liquid ratio $(S / L)$ on the efficiency of metal leaching from crushed material using alkaline solution (Solid: $5 \mathrm{~g}$; alkaline concentration: $10 \%(\mathrm{w} / \mathrm{w}) ; \mathrm{Na}_{2} \mathrm{CO}_{3} / \mathrm{NaHCO}_{3}$ : $1: 2$; alkaline solution volume: $5.3-25.2 \mathrm{~mL}$; agitation time: $2 \mathrm{~h}$; $\mathrm{T}: 23 \pm 2{ }^{\circ} \mathrm{C}$ )

\begin{tabular}{|c|c|c|c|c|c|}
\hline \multirow[t]{3}{*}{ Metal } & \multicolumn{5}{|c|}{$\begin{array}{l}\mathrm{Na}_{2} \mathrm{CO}_{3} / \mathrm{NaHCO}_{3}(\mathrm{~mL}) \\
S / L \text { ratio }(1: \mathrm{N})\end{array}$} \\
\hline & 5.3 & 10.2 & 15.4 & 20.3 & 25.2 \\
\hline & $1: 1$ & $1: 2$ & $1: 3$ & $1: 4$ & $1: 5$ \\
\hline $\mathrm{Al}$ & 0.12 & 0.29 & 0.34 & 0.32 & 0.35 \\
\hline Мо & 21.53 & 43.98 & 53.87 & 53.81 & 59.94 \\
\hline Co & 0.00 & 0 & 0 & 0 & 0 \\
\hline
\end{tabular}

$S / L$ ratio represents the mass of solid divided by the actual volume of leachate; the wetting of the catalyst with the leaching solution represented $2.5 \mathrm{mg}$ of solution and this means that compared to the used volumes of leaching solutions the $S / L$ ratio could be written $1: 2,1: 3$, $1: 4,1: 5$ and $1: 6$

poorly affected by this molar ratio. On the opposite hand, the alkaline leaching allows recovering $18.5-21.5 \%$ of Mo with a limited effect of the ratio between carbonate and bicarbonate: molybdenum leaching is slightly higher with a 1:2 $\mathrm{Na}_{2} \mathrm{CO}_{3} / \mathrm{NaHCO}_{3}$ ratio. Alkaline solutions readily dissolve $\mathrm{Mo}(\mathrm{VI})$, which is the oxidized form present on the catalyst [32], to form molybdate species while the other metals on the catalyst cannot be dissolved in alkaline conditions. These conditions allow recovering selectively Mo from the catalyst. This is consistent with the comments of Ferella et al. [45] who reported the selective extraction of Mo and V from HDS catalysts using alkali leaching; partial leaching of alumina was reported while cobalt was segregated in the solid residue. Mo was dissolved through the reaction:

$\mathrm{MoO}_{3}+\mathrm{Na}_{2} \mathrm{CO}_{3} \rightarrow \mathrm{Na}_{2} \mathrm{MoO}_{4}+\mathrm{CO}_{2}$.

Effect of $S / L$ ratio Increasing the volume of alkaline leaching solution does not affect $\mathrm{Al}$ and Co leaching while the recovery of Mo from the catalyst is increased (Table 8). The highest increase in metal recovery is observed when volume of leaching agent is increased from $5 \mathrm{~mL}$ to $15 \mathrm{~mL}(S / L$ ratio increasing from 1:1 to 1:3). Above, the increase in Mo leaching is not sufficient for justifying the increased consumption of the reagent. In addition, the concentration of molybdenum in the leachate progressively decreases when increasing the volume of leaching agent. A good compromise between Mo desorption yield and concentration crite- 
Table 9 Effect of $\mathrm{Na}_{2} \mathrm{CO}_{3} / \mathrm{NaHCO}_{3}$ concentration $\left(\mathrm{g} \mathrm{L}^{-1}\right)$ on the efficiency of metal leaching from crushed material (Solid: $5 \mathrm{~g}$; alkaline concentration: $10-30 \%(\mathrm{w} / \mathrm{w}) ; \mathrm{Na}_{2} \mathrm{CO}_{3} / \mathrm{NaHCO}_{3}$ : 1:2; alkaline solution volume: $15.4 \mathrm{~mL}$; agitation time: $2 \mathrm{~h}$; T: $23 \pm 2{ }^{\circ} \mathrm{C}$ )

\begin{tabular}{llllll}
\hline Metal & \multicolumn{5}{l}{$\mathrm{Na}_{2} \mathrm{CO}_{3} / \mathrm{NaHCO}_{3}$ concentration $(\%, w / w)$} \\
\cline { 2 - 6 } & 10 & 15 & 20 & 25 & 30 \\
\hline $\mathrm{Al}$ & 0.34 & 0.47 & 0.45 & 0.45 & 0.43 \\
Mo & 53.87 & 72.63 & 69.77 & 69.76 & 66.39 \\
$\mathrm{Co}$ & 0 & 0 & 0 & 0 & 0 \\
\hline
\end{tabular}

Table 10 Effect of temperature $\left({ }^{\circ} \mathrm{C}\right)$ on the efficiency of metal leaching from crushed material using alkaline solutions (Solid: $5 \mathrm{~g}$; alkaline concentration: $15 \%$ (w/w); $\mathrm{Na}_{2} \mathrm{CO}_{3} / \mathrm{NaHCO}_{3}$ : $1: 2$; alkaline solution volume: $15.4 \mathrm{~mL}$; agitation time: $2 \mathrm{~h}$; $\mathrm{T}$ : $\left.25-100{ }^{\circ} \mathrm{C}\right)$

rion appears to be using a 1:3 $S / L$ ratio with the $1: 2$ molar ratio $\mathrm{Na}_{2} \mathrm{CO}_{3} / \mathrm{NaHCO}_{3}$. ( $10 \%$ w/w carbonate/bicarbonate concentration): the leaching yields almost $54 \%$ while the concentration of Mo in the leachate reaches up to $12.4 \mathrm{~g} \mathrm{Mo}$ $\mathrm{L}^{-1}$.

Effect of carbonate/bicarbonate concentration When varying alkaline concentration from $10 \%$ to $30 \%$, Al leaching does not exceed $0.47 \%$ while cobalt is not recovered at all from the catalyst, on the opposite hand the maximum Mo leaching (i.e., $72.6 \%$ ) is obtained at 15\% w/w (Table 9). Molybdenum recovery decreases again when the concentration of the alkaline leaching agent exceeds $15 \%$ (w/w).

Effect of temperature Carbonate/bicarbonate mixture being a mild leaching agent, playing with temperature may influence the efficiency of the process. This is confirmed by Table 10: increasing the temperature from 23 to $100{ }^{\circ} \mathrm{C}$ allows dissolving very small amounts of $\mathrm{Al}$ and Co (less than 2 and $1 \%$, respectively); on the opposite hand, molybdenum leaching is significantly increased from $72.6 \%$ to $86.0 \%$. The concentrations of $\mathrm{Al}, \mathrm{Co}$ and $\mathrm{Mo}$ reach up to $1.63 \mathrm{~g} \mathrm{Al} \mathrm{L}^{-1}, 47.5 \mathrm{mg} \mathrm{Co} \mathrm{L}^{-1}$ and $19.95 \mathrm{~g} \mathrm{Mo} \mathrm{L}^{-1}$. The leaching conditions are remarkably selective for Mo over Co but significant amounts of the support element (i.e., $\mathrm{Al}$ ) are simultaneously leached.

Effect of leaching time Increasing the reaction time slightly increased $\mathrm{Al}$ and Co leaching (Table 11); however, even after $6 \mathrm{~h}$ of contact the leaching efficiencies do not exceed 2.3 and $1.9 \%$, respectively. For Mo the leaching efficiency increases up to $95.2 \%$ after $5 \mathrm{~h}$ of reaction while above
Table 11 Effect of agitation time (h) upon the leaching efficiencies of metal values from crushed material using alkaline solutions (Solid: $5 \mathrm{~g}$; alkaline concentration: $15 \%(\mathrm{w} / \mathrm{w}) ; \mathrm{Na}_{2} \mathrm{CO}_{3} / \mathrm{NaHCO}_{3}: 1: 2 ; \mathrm{S} / \mathrm{L}$ ratio; 1:4,alkaline solution volume: $\left.15.4 \mathrm{~mL} ; \mathrm{T}: 100{ }^{\circ} \mathrm{C}\left( \pm 2{ }^{\circ} \mathrm{C}\right)\right)$

\begin{tabular}{llllll}
\hline Metal & \multicolumn{5}{l}{ Agitation time $(\mathrm{h})$} \\
\cline { 2 - 6 } & 2 & 3 & 4 & 5 & 6 \\
\hline Al & 1.92 & 1.92 & 1.98 & 2.09 & 2.25 \\
Mo & 86.05 & 88.32 & 91.36 & 95.19 & 95.12 \\
Co & 0.86 & 0.95 & 1.5 & 1.68 & 1.86 \\
\hline
\end{tabular}

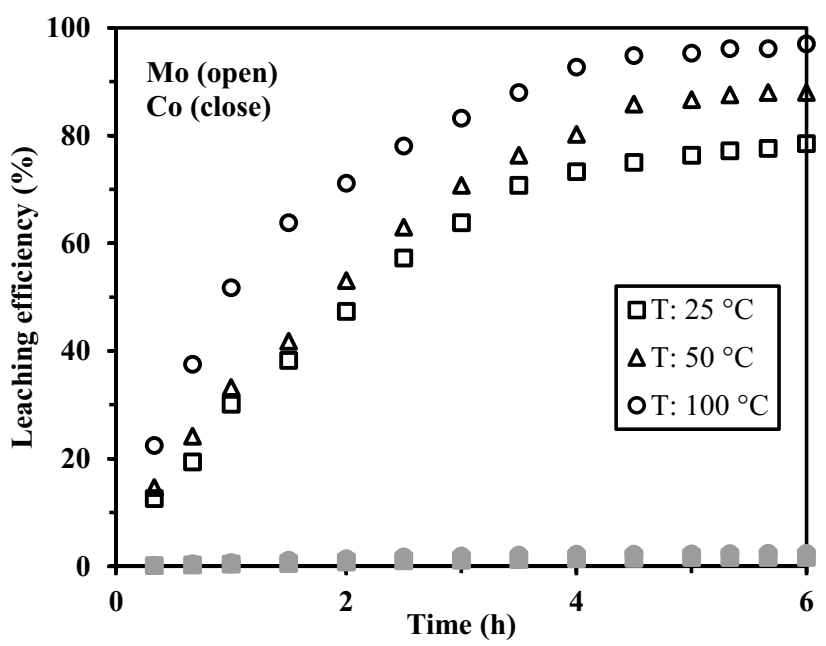

Fig. 2 Kinetics of Co and Mo alkaline leaching at different temperatures (Solid: $5 \mathrm{~g}$; alkaline concentration: $15 \%$ (w/w) $\mathrm{Na}_{2} \mathrm{CO}_{3} /$ $\mathrm{NaHCO}_{3}$ : 1:2; alkaline solution volume: $15.4 \mathrm{~mL}$; $\mathrm{T}: 25-100{ }^{\circ} \mathrm{C}$ )

metal recovery tends to stabilize. Then, it is not necessary increasing the reaction time above $5 \mathrm{~h}$ : the metal concen-

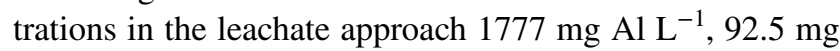
$\mathrm{Co} \mathrm{L}^{-1}$ and up to $22.07 \mathrm{~g} \mathrm{Mo}^{-1}$. As for acidic leaching, the equations for SCM controlled by film diffusion, particle layer diffusion and reaction rate have been tested (see Table AM5, Additional Material Section). None of the models fits experimental profiles for Mo (the leaching of other metals was negligible and the kinetic profiles are not meaningful).

Complementary tests were performed to evaluate the impact of temperature on leaching kinetics (Fig. 2). Table AM7 reports the rate coefficients for Co and Mo leaching using the different equations. Co leaching is limited to less than 3\% (consistently with previous results): increasing the temperature to $100{ }^{\circ} \mathrm{C}$ did not change the leaching efficiency and the kinetics were not significantly changed (overlapping of the curves). The rate coefficients for Mo were analyzed using the Arrhenius equation (Eq. 8; Figure AM4, see Additional Material Section) and the coefficients obtained for both SCM-PLDC and SCM-RC equations: the activation energy reaches $9.0( \pm 0.33) \mathrm{kJ} \mathrm{mol}^{-1}$; this is slightly lower 
than the activation energy for sulfuric acid leaching (i.e., $10.5 \mathrm{~kJ} \mathrm{~mol}^{-1}$ ).

\section{Precipitation of metals from pregnant leaching liquors}

\section{Acid leachates}

Production and characterization of acid leachate The optimization of the acidic leaching concluded that the best conditions for metal recovery of metals from catalysts correspond to the use of sulfuric acid solution $(2.5 \mathrm{~L})$ at the concentration of $300 \mathrm{~g} \mathrm{~L}^{-1}$ with $S / L$ ratio of $1: 5$ maintaining the temperature to $50 \pm 2{ }^{\circ} \mathrm{C}$ under agitation for $4 \mathrm{~h}$. The leaching efficiencies reach up to $65.6 \%$ for $\mathrm{Al}, 98.8 \%$ for Co and $99.9 \%$ for Mo. These experimental conditions have been applied for treating $500 \mathrm{~g}$ of catalyst under an agitation speed of $400 \mathrm{rpm}$. At the end of the process, the aqueous phase was recovered by filtration under vacuum and the metal concentrations were determined: $42.485 \mathrm{~g} \mathrm{Al} \mathrm{L}^{-1}$, $4.097 \mathrm{~g} \mathrm{Co} \mathrm{L}^{-1}$ and $17.27 \mathrm{~g} \mathrm{Mo} \mathrm{L}^{-1}$. This corresponds to leaching efficiencies of $66.6,99.0$ and $99.1 \%$ for Al, Co and Mo, respectively: these results are consistent with the results obtained on small-size tests. This is also consistent with the SEM-EDX analysis of the residue of acidic leaching (Figure AM5, see Additional Material Section): Co and Mo have disappeared from the SEM-EDX spectra, while Al content is decreased to $4.39 \%$ (compared to $23-27 \%$ in the pristine catalyst material). The residue is mainly constituted of silicate that was not dissolved by sulfuric acid solution [46]: $\mathrm{Si}$ represents $30.45 \%$ of the residue contrary to only $8.1 \%$ for pristine catalyst. It is interesting to observe that the values of leaching efficiencies are remarkably consistent with the values obtained in the preliminary optimization study (see Sect. 3.2.1.5.).

Precipitation of metal ions from acidic leachates by $\mathrm{pH}$ control The $\mathrm{pH}$ of acid leachates was controlled between $\mathrm{pH} 1$ and 5 using $\mathrm{NaOH}$ or $\mathrm{H}_{2} \mathrm{SO}_{4}(5 \mathrm{M})$ solutions (Figure AM6, see Additional Material Section). The precipitation of the different metals increases with $\mathrm{pH}$ : metal precipitation is negligible at $\mathrm{pH} 1-2$ and becomes appreciable at $\mathrm{pH} 5$. It is noteworthy that the three metal ions have very similar precipitation profiles: the metal ions cannot be separated by a simple precipitation method.

Selective separation by sulfide precipitation Sulfur dissociation properties and metal sulfide precipitation are strongly influenced by the $\mathrm{pH}$ of the solution. This may explain that sulfide precipitation process is widely used for metal separation [47]; this method is usually more selective than simple pH-controlled alkali precipitation. Different metal sulfides/ bisulfides may be formed depending on the metal and the
$\mathrm{pH}$, including $\mathrm{M}(\mathrm{SH})^{+}, \mathrm{M}_{2}(\mathrm{SH})^{3+}$ and $\mathrm{M}_{3}(\mathrm{SH})^{5+}$ [48], or simple sulfur complexes MS [49]. In the separation of Mo and Co from spent HDS catalysts, Vemic et al. used sodium sulfide for the selective precipitation of metal ions [21]. The precipitation of the metal ions with sodium sulfide was first investigated at $\mathrm{pH} 2$ using increasing amounts of sulfide (10 40\%, w/w) (Fig. 3). Increasing sulfide concentration slightly increases metal precipitation: with $40 \% \mathrm{Na}_{2} \mathrm{~S}$ concentration the precipitation leads to the recovery of $8.9,97.0$ and $97.6 \%$ for $\mathrm{Al}, \mathrm{Co}$ and $\mathrm{Mo}$, respectively. This means that the precipitate contains significant amounts of aluminum that cannot be easily separated from the precipitate. Decreasing the $\mathrm{pH}$ to 1 (and maintaining the same sodium sulfide concentrations) decreases the precipitation of $\mathrm{Al}$ to about 1.2\% (Figure AM7, see Additional Material Section) while maintaining almost constant the precipitation of $\mathrm{Co}$ and $\mathrm{Mo}$, at a very high level (i.e., $99.7 \%$ and $99.9 \%$ for $\mathrm{Co}$ and $\mathrm{Mo}$, respectively). Controlling the $\mathrm{pH}$ to 1 with a $\mathrm{Na}_{2} \mathrm{~S}$ concentration close to $40 \%$ is a solution for selectively recovering the valuable metals. In the sulfide precipitation of Mo, Co and $\mathrm{Ni}$ from synthetic leachates, Vimic et al. [21] suggested processing the precipitation of $\mathrm{Ni}$ and $\mathrm{Co}$ (as sulfide precipitates) at $\mathrm{pH} 4$, before precipitating $\mathrm{Mo}$ at $\mathrm{pH} 1$. With real acidic leachates, the presence of zinc decreases the efficiency of the process. In the present case, the leachates contain $\mathrm{Al}$, processing the precipitation of $\mathrm{Co}$ at higher $\mathrm{pH}$ (i.e., 4-5) would also lead to co-precipitation of $\mathrm{Al}$ and make difficult the separation of the different metals. For these reasons, it is preferred separating Mo and Co as precipitates at $\mathrm{pH} 1$ while maintaining aluminum in solution.

After Mo and Co precipitation at $\mathrm{pH} \mathrm{1,} \mathrm{the} \mathrm{filtrate,}$ which contains an $\mathrm{Al}$ concentration close to $41.99 \mathrm{~g} \mathrm{~L}^{-1}$, is treated by alkaline precipitation using $30 \% \mathrm{NaOH}(\mathrm{w} / \mathrm{w})$ solution and adjusting the $\mathrm{pH}$ to 5 . A white precipitate

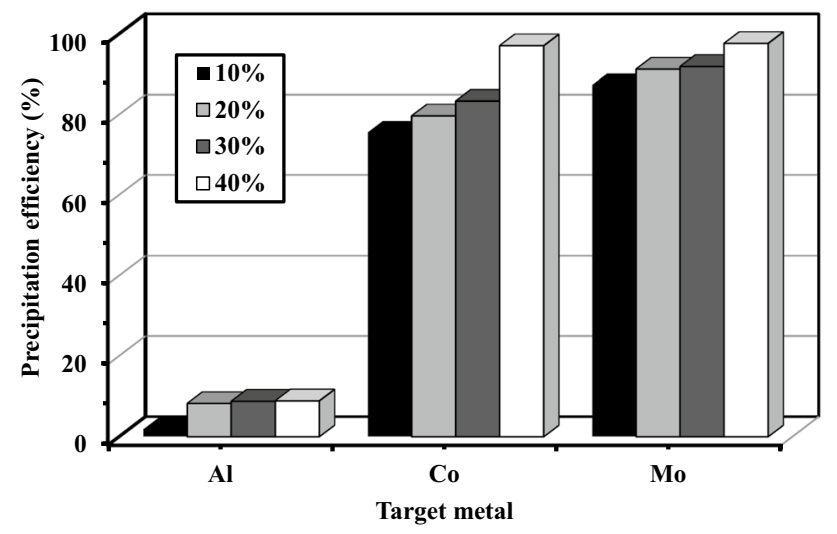

Fig. 3 Effect of sodium sulfide concentration (10-40\%, w/w) on precipitation of $\mathrm{Al}, \mathrm{Co}$ and $\mathrm{Mo}$ at $\mathrm{pH} 2$ (volume of solution: $130 \mathrm{~mL}$ per L of leachate, $\mathrm{T}: 23 \pm 2{ }^{\circ} \mathrm{C}$; agitation time: $1 \mathrm{~h}$; $\mathrm{pH}$ control with $5 \mathrm{M} \mathrm{NaOH} / \mathrm{H}_{2} \mathrm{SO}_{4}$ solutions; $\mathrm{C}_{0}: 40.45 \mathrm{~g} \mathrm{Al} \mathrm{L}^{-1}, 4.09 \mathrm{~g} \mathrm{Co} \mathrm{L}^{-1}$ and 17.25 $\mathrm{g} \mathrm{Mo} \mathrm{L}^{-1}$ ) 
appears, the SEM-EDX analysis of this precipitate (Figure AM8, see Additional Material Section) confirms that molybdenum and cobalt are correctly separated from aluminum since the elements do not appear on EDX spectrum. Al content reached $20.1 \%$ (accompanied by $\mathrm{O}$ element: $70.9 \%$ ) and there are traces of sulfide (i.e., 8.8\%) and $\mathrm{Na}$ element (i.e., $0.2 \%$ ). It is noteworthy that the presence of sulfide ions contributes to improve the precipitation of aluminum hydroxide according to [50]:

$$
\begin{aligned}
& \mathrm{Al}^{3+}+3 \mathrm{NaOH} \leftrightarrow \mathrm{Al}(\mathrm{OH})_{3, s}+3 \mathrm{Na}^{+} \\
& 2 \mathrm{Al}^{3+}+3 \mathrm{~S}^{-}+6 \mathrm{H}_{2} \mathrm{O} \leftrightarrow 2 \mathrm{Al}(\mathrm{OH})_{3, s}+3 \mathrm{H}_{2} \mathrm{~S} .
\end{aligned}
$$

Selective separation of Co and Mo from sulfide precipitate Figure AM9 (see Additional Material Section) shows the EDX analysis of the sulfide precipitate of acidic leachate $\left[\mathrm{pH} 1,40 \%(\mathrm{w} / \mathrm{w}) \mathrm{Na}_{2} \mathrm{~S}\right]$. $\mathrm{Al}$ is not appearing in the EDX spectrum as a confirmation of the selective separation of valuable metals from the metal of the catalyst support: Co element reaches $9.9 \%$ (against $40.3 \%$ for Mo element). The $\mathrm{Mo} / \mathrm{Co}$ mass ratio in the pristine catalyst (close to 4.8 ) is of the same order than in the mixed precipitate (i.e., 4.1); however, after metal leaching and selective reprecipitation the $\mathrm{Mo} / \mathrm{Co}$ atomic ratio decreases from 2.9 to 1.2 .

To separate Mo from Co, an alkaline leaching of the precipitate was carried out. The Co/Mo cake (109.7 g, resulting from the acidic leaching and final sulfide precipitation of $500 \mathrm{~g}$ of pristine catalyst) is mixed with $440 \mathrm{~mL}$ of $15 \%$ $(\mathrm{w} / \mathrm{w})$ alkaline solution (1:2 carbonate/bicarbonate mixture) for $4 \mathrm{~h}$ (under agitation, $400 \mathrm{rpm}$ ) at $100 \pm 2{ }^{\circ} \mathrm{C}$. The filtrate was recovered for further precipitation of Mo using $\mathrm{Na}_{2} \mathrm{~S}$ after neutralization by sulfuric acid solution while the insoluble product consists of Co precipitate, which was washed up two times with hot water to remove unreacted carbonate and purify the insoluble Co precipitate (about $22 \mathrm{~g}$ ). The filtrate $(390 \mathrm{~mL})$ is neutralized using sulfuric acid before processing the precipitation of molybdenum with sodium sulfide ( $150 \mathrm{~mL}$ of a $40 \% \mathrm{w} / \mathrm{w} \mathrm{Na} 2 \mathrm{~S}$ solution for $1 \mathrm{~h}$ ). Figure AM10 (see Additional Material Section) shows the EDX analysis of the precipitate obtained after carbonate leaching of Co/Mo cake (Mo dissolving) and final acidic Mo precipitation (after calcination at $900{ }^{\circ} \mathrm{C}$ ). These spectra show relatively pure products despite the presence of traces of sodium (i.e., around $0.4 \%$ ) in molybdenum sulfide precipitate.

Figures AM11 (see Additional Material Section) shows the EDX spectra of the solid residue after alkaline leaching of Mo from the Co/Mo, after two successive steps of solid washing of Co-based solid. After the second step of purification, the traces of aluminum disappear and a relatively pure Co-based product (cobalt sulfide) is obtained (Co elements counts for $43.0 \%$ and S element for $14.4 \%$ ); the presence of O element (about $42.6 \%$ ) is probably associated to an incomplete drying of the precipitate or the moistening of the material.

\section{Alkaline leachates}

Production and characterization of alkaline leaching liquor The production of the alkaline pregnant leaching liquor was performed in a reactor maintained under agitation and under reflux at $100 \pm 2{ }^{\circ} \mathrm{C}$ for $5 \mathrm{~h}$. The catalyst $(500 \mathrm{~g})$ was mixed with $2.5 \mathrm{~L}$ of $15 \% \mathrm{Na}_{2} \mathrm{CO}_{3} / \mathrm{NaHCO}_{3}$ solution $(1: 2$ mixture). The remaining solid was washed three times with $500 \mathrm{~mL}$ of hot water (i.e., $S / L=1: 1$ ) for $30 \mathrm{~min}$; this step is supposed to dissolve any carbonate present in the solid. The pre-treatment allows reducing the amount of acid to be used in the next step for acid leaching and contributes to improve the competitiveness of Mo recovery. It is noteworthy that washing solution can then be recycled for preparing the leaching step for the processing of alkaline leachates. Figure AM12 (see Additional Material Section) shows the residue after carbonate leaching process indicating removal of Mo; the residue contains mainly $\mathrm{Si}, \mathrm{Al}$ and $\mathrm{Co}$.

\section{Selective Mo recovery}

In a second step, $\mathrm{Na}_{2} \mathrm{~S}$ was added to the solution to reach a $40 \%(\mathrm{w} / \mathrm{w})$ concentration. The step allows precipitating Mo from the alkaline leachate as molybdenum sulfide (producing about $46 \mathrm{~g}$ of solid, corresponding to precipitation efficiency close to 98.2\%). Figure AM13 (see Additional Material Section) shows the SEM-EDX analysis of the molybdenum sulfide precipitate (S element is in the range 61.0-62.2\%, and Mo element between 35.9 and 39.0\%): small traces of sodium can be detected (around 1.5\%); however, other elements initially present in the catalyst are negligible. This is consistent with the ICP-AES analysis that shows negligible concentrations of $\mathrm{Al}, \mathrm{Si}$, and $\mathrm{Co}$ in the alkaline leachate, this also confirms the results obtained in the preliminary study. After burning/roasting at $900{ }^{\circ} \mathrm{C}$, the molybdenum sulfide residue only contains molybdenum (Figure AM14, see Additional Material Section).

\section{Selective recovery of $\mathrm{Si}$}

The residue of alkaline leaching (after water washing) that represents an amount of $455 \mathrm{~g}$ (over the initial amount of $500 \mathrm{~g}$ of catalyst) was mixed with $2.3 \mathrm{~L}$ of sulfuric acid (300 $\mathrm{g} \mathrm{L}^{-1}$ concentration) for $4 \mathrm{~h}$ at $50{ }^{\circ} \mathrm{C}$ under agitation (speed $400 \mathrm{rpm}$ ). The $\mathrm{pH}$ of the filtrate was controlled to 2 using concentrated sulfuric acid. Acidic treatment allows (a) completely removing cobalt, (b) removing the last traces of Mo, and (c) removing most of Al. After vacuum filtration, the solid residue was collected and analyzed by SEM-EDX (Figure AM15, see Additional Material Section, after drying 
at $100{ }^{\circ} \mathrm{C}$ for $10 \mathrm{~h}$ ): silicate-based compound is predominant in the solid phase (i.e., Si: $35.5 \%$ and O: $58.5 \%$ ) with traces of aluminum (about $0.71 \%$, w/w) and carbon (around $5.3 \%$ ). The filtrate is supposed to contain aluminum, and cobalt.

\section{Selective recovery of Co}

The sulfuric acid filtrate (after Mo and Si removal) was precipitated by controlling the $\mathrm{pH}$ to 1 and adding sodium sulfide $(200 \mathrm{~mL}$ of $40 \% \mathrm{w} / \mathrm{w} \mathrm{Na} 2 \mathrm{~S})$ under agitation for $2 \mathrm{~h}$, at room temperature. This step allows producing cobalt sulfide with high purity, as shown on Figure AM16 (see Additional Material Section). The weight fractions of Co and $\mathrm{S}$ elements are close to $34.9 \%$ and $24.6 \%$, respectively, the remaining major element is oxygen (around 40.5\%).

\section{Selective recovery of $\mathrm{Al}$}

A final filtration step (after Co removal) allowed recovering a white precipitate by $\mathrm{pH}$ control at 5 (using $450 \mathrm{~mL}$ of $30 \% \mathrm{NaOH}$ w/w solution) under agitation (agitation speed: $400 \mathrm{rpm}$ ) for $1 \mathrm{~h}$. SEM-EDX analysis confirms the purity of the aluminum hydroxide (Figure AM17, see Additional Material Section, after drying at $100{ }^{\circ} \mathrm{C}$ for $10 \mathrm{~h}$ ). Aluminum represents $22.8-25.0 \%$, while oxygen varies between $69.4 \%$ and $70.9 \%$. Traces of S element (i.e., 3.8-4.4\%) and Na element (i.e., 1.2-2.5\%) are also observed.

\section{Suggested flowsheet for metal recovery from waste products}

Baes and Mesmer [51] deeply investigated the hydrolysis of cations. Aluminum has a minimal solubility close to neutral pH: in acidic conditions $\mathrm{Al}$ (III) is solubilized; in alkaline conditions the solubilized aluminum appears under the form of $\mathrm{Al}(\mathrm{OH})_{4}{ }^{-}$. On the other hand, cobalt is poorly soluble in alkaline conditions, requiring acidic conditions for increasing the solubility. In the case of molybdenum, a broad range of $\mathrm{pH}$ conditions is favorable to metal solubilization; however, in very acidic conditions the solubility of molybdenum is decreased (formation of $\mathrm{MoO}_{3}$ ). Obviously, these general trends may be affected by the composition of the solution, the oxidation state of the metal in the catalyst, and the type of acid or alkaline agent used for metal leaching. Metal sulfate precipitation or carbonate complexation of metals (respectively) can affect the overall solubility of target metals.

Figure 4 shows the flowsheet of catalyst treatment for the selective recovery of metals. The sequence of operating steps is briefly reminded for both acid and alkaline leaching
Fig. 4 Flowsheet for the separation of $\mathrm{Al}$, Co and Mo from the crude catalyst material

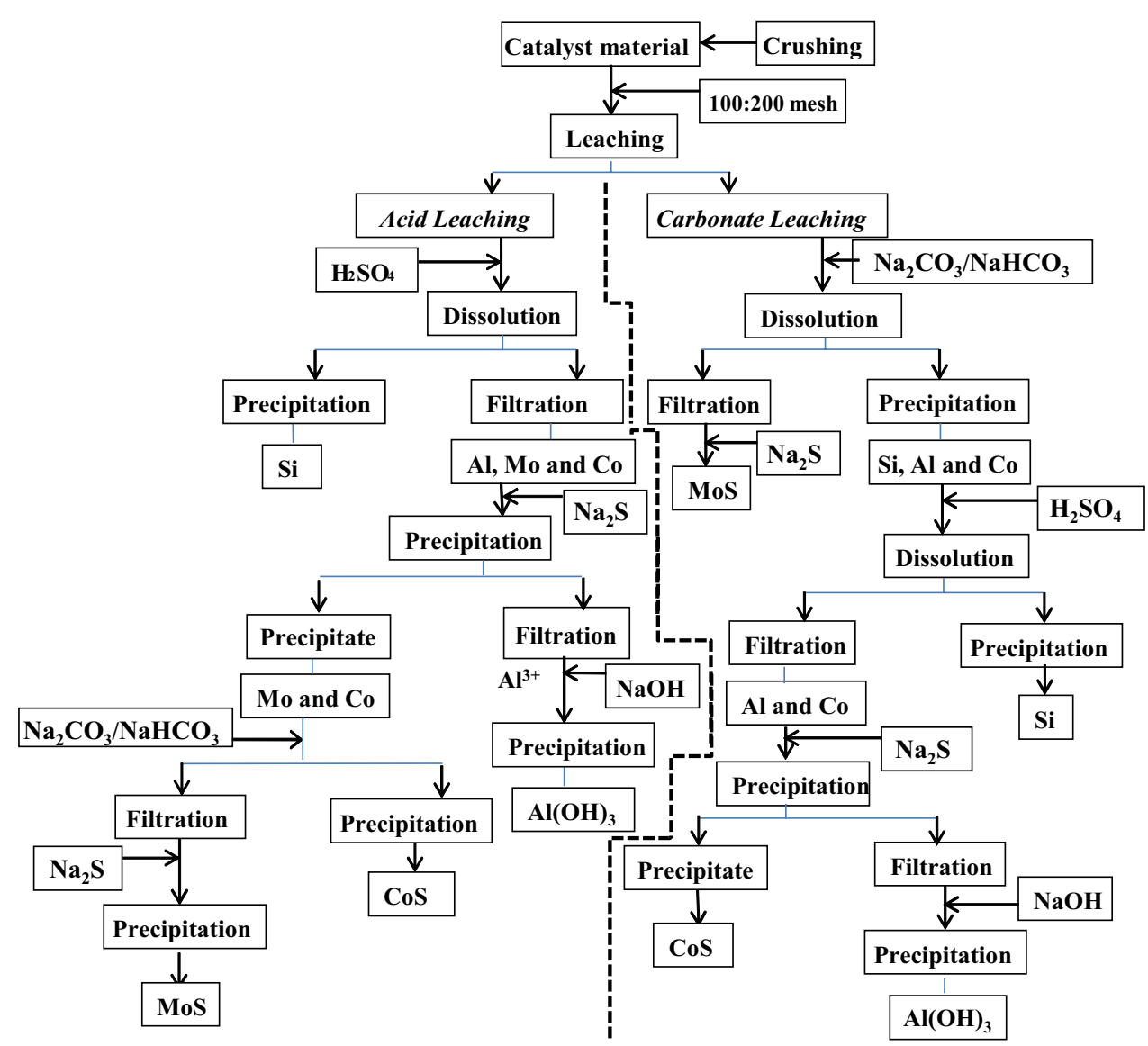


strategies. Tables 12 and 13 show the percentage distribution of target metals (i.e., Al, Co, and Mo) in the different compartments, i.e., liquid and solid phases or residues generated in the process. The mass balance is respected in most cases: a little variation is observed for Mo in the acid leaching process (total balance differs by $1 \%$ ). The recovery of valuable metals (i.e., Co and Mo) is almost quantitative: higher than $99 \%$ for Co, and higher than $97 \%$ for Mo. In addition, the recovery of these metals is very selective as identified on EDX spectra of cobalt and molybdenum sulfides (pure products); the distribution of Co and Mo in the different compartments is also clearly showing that Co and Mo are selectively recovered in the two compartments, though some traces can be found in some liquid and solid phases the relative loss amount does not exceed a few percent. The flowsheet clearly shows that both the acid and alkaline leaching processes allows recovering selectively the target metals, providing an appropriate selection of precipitation and purification steps are applied.

Table AM8 (a\&b) (see Additional Material Section) summarizes the main costs for expenditures (reagents and energy for thermal control) for both the acid leaching and the alkaline leaching processes. These data (which can be only considered as rough estimates of the operative costs; requiring more rigorous calculations for commercial application) demonstrate that the acidic leaching is slightly cheaper than the alkaline leaching; the difference represents only $4 €$ per $\mathrm{kg}$ of processed catalyst.

\section{Conclusion}

A series of leaching (acid or alkaline), selective precipitation (using sulfide) and purification steps (alkaline leaching and precipitation) can efficiently be used for selective recovery of cobalt and molybdenum from hydrodesulphurization catalysts (non-spent but out-of-range materials). Both the acidic and the alkaline leaching procedures
Table 13 Distribution of metals (Al, Co and Mo) in the different compartments of the alkaline leaching process (normalized values)

\begin{tabular}{|c|c|c|c|c|}
\hline Compartment & \# & $\mathrm{Al}$ & Co & Mo \\
\hline Aqueous phase after MoS precipitation & $\mathrm{C} 1$ & 2.0 & 1.0 & 2.4 \\
\hline $\begin{array}{l}\text { Aqueous phase after final } \mathrm{Al}(\mathrm{OH})_{3} \text { precipita- } \\
\text { tion }\end{array}$ & $\mathrm{C} 2$ & 0.6 & 2.3 & 0.5 \\
\hline $\begin{array}{l}\text { Solid residue after acid leaching of } \mathrm{Co} / \mathrm{Mo} \\
\text { cake }\end{array}$ & $\mathrm{C} 3$ & 0.9 & 0.1 & 0.0 \\
\hline Solid phase in MoS precipitate & $\mathrm{C} 4$ & 0.0 & 0.0 & 95.5 \\
\hline Solid phase in CoS precipitate & $\mathrm{C} 5$ & 0.6 & 94.5 & 0.0 \\
\hline Solid phase in $\mathrm{Al}(\mathrm{OH})_{3}$ precipitate & C6 & 95.9 & 2.0 & 1.6 \\
\hline $\begin{array}{l}\text { Effective metal recovery in selective } \\
\text { compartment }^{\mathrm{a}}\end{array}$ & & 95.9 & 94.5 & 95.5 \\
\hline
\end{tabular}

Bold values identify the compartments where the greatest amounts of selected metal ions are recovered

${ }^{\mathrm{a}}$ : calculated by comparison to initial metal amount in $500 \mathrm{~g}$ of catalyst; mass balance close to $100 \%$

can be used for quantitative recovery of valuable metals. SEM-EDX characterization on the selective precipitates and residue confirm the high efficiency in both recovery and selectivity (purity of elaborated solids). The possibility to use both acid and alkaline treatment lines offers great flexibility in the selection of methods, depending on the characteristics of the waste products. These different strategies provide useful information for the valorization of metals from out-of-range products during the manufacturing of catalysts. This information could be also useful for the treatment of spent catalyst although the presence of poisonous substances, unburnt residues may alter the efficiency of the recovery process. This may help in the design of processes for metal recycling from industrial manufacturing of catalysts and other metal-bearing systems, in coherence with the international policies and politics for waste recycling.
Table 12 Distribution of metals (Al, Co and Mo) in the different compartments of the acid leaching process (normalized values)

\begin{tabular}{lllll}
\hline Compartment & $\#$ & Al & Co & Mo \\
\hline Aqueous phase after $\mathrm{Na}_{2} \mathrm{~S}$ precipitation of acid leachate & $\mathrm{A} 1$ & $\mathbf{6 6 . 6}$ & 0.3 & 0.1 \\
Aqueous residue (End of the process) & $\mathrm{A} 2$ & 0.0 & 1.0 & 0.6 \\
Solid residue after acid leaching & $\mathrm{A} 3$ & 33.4 & 1.0 & 0.9 \\
Solid phase in CoS precipitate & $\mathrm{A} 4$ & 0.0 & $\mathbf{9 7 . 7}$ & 1.8 \\
Solid phase in MoS precipitate & $\mathrm{A} 5$ & 0.0 & 0.0 & $\mathbf{9 6 . 6}$ \\
Effective metal recovery in selective compartments $^{\mathrm{a}}$ & & 66.6 & 97.7 & 95.7 \\
\hline
\end{tabular}

Bold values identify the compartments where the greatest amounts of selected metal ions are recovered ${ }^{\mathrm{a}}$ Calculated by comparison to initial metal amount in $500 \mathrm{~g}$ of catalyst; mass balance on $\mathrm{Al}$ and Co close to $100 \%$, and close to $99 \%$ for Mo 
Acknowledgements Authors acknowledge the financial support of French Government (Institut Français d'Egypte, French Embassy in Egypt) through the fellowship granted to M.F. Hamza.

\section{References}

1. Mohapatra D, Park KH (2007) Selective recovery of Mo, Co and $\mathrm{Al}$ from spent $\mathrm{Co} / \mathrm{Mo} / \mathrm{gamma}-\mathrm{Al}_{2} \mathrm{O}_{3}$ catalyst: Effect of calcination temperature. J Environ Sci Health Part A Toxic/Hazard Subst Environ Eng 42(4):507-515

2. Le H-L, Yamasue E, Okumura H, Ishihara KN (2014) Improving sustainable recovery of metals from waste printed circuit boards by the primary copper smelter process. J Mater Cycles Waste Manag 16(2):298-305

3. Huang K, Inoue K, Harada H, Kawakita H, Ohto K (2011) Leaching of heavy metals by citric acid from fly ash generated in municipal waste incineration plants. J Mater Cycles Waste Manag 13(2):118-126

4. Rudnik E, Pierzynka M, Handzlik P (2016) Ammoniacal leaching and recovery of copper from alloyed low-grade e-waste. J Mater Cycles Waste Manag 18(2):318-328

5. Navarro R, Guzman J, Saucedo I, Revilla J, Guibal E (2007) Vanadium recovery from oil fly ash by leaching, precipitation and solvent extraction processes. Waste Manag (Oxford) 27(3):425-438

6. Liu J, Qiu ZF, Yang J, Cao LM, Zhang W (2016) Recovery of Mo and $\mathrm{Ni}$ from spent acrylonitrile catalysts using an oxidation leaching-chemical precipitation technique. Hydrometallurgy 164:64-70

7. Pinto ISS, Soares H (2012) Selective leaching of molybdenum from spent hydrodesulphurisation catalysts using ultrasound and microwave methods. Hydrometallurgy 129:19-25

8. Barik SP, Park KH, Parhi PK, Park JT (2012) Direct leaching of molybdenum and cobalt from spent hydrodesulphurization catalyst with sulphuric acid. Hydrometallurgy 111:46-51

9. Szymczycha-Madeja A (2011) Kinetics of Mo, Ni, V and Al leaching from a spent hydrodesulphurization catalyst in a solution containing oxalic acid and hydrogen peroxide. J Hazard Mater 186(2-3):2157-2161

10. Ruiz V, Meux E, Schneider M, Georgeaudl V (2011) Hydrometallurgical treatment for valuable metals recovery from spent $\mathrm{CoMo} / \mathrm{Al}_{2} \mathrm{O}_{3}$ catalyst. 2. Oxidative leaching of an unroasted catalystc using $\mathrm{H}_{2} \mathrm{O}_{2}$. Ind Eng Chem Res 50(9):5307-5315

11. Kim HI, Park KH, Mishra D (2009) Sulfuric acid baking and leaching of spent $\mathrm{Co}-\mathrm{Mo} / \mathrm{Al}_{2} \mathrm{O}_{3}$ catalyst. J Hazard Mater 166(2-3):1540-1544

12. Lai YC, Lee WJ, Huang KL, Wu CM (2008) Metal recovery from spent hydrodesulfurization catalysts using a combined acid-leaching and electrolysis process. J Hazard Mater 154(1-3):588-594

13. Wu Y, Wang B, Zhang Q, Li R, Sun C, Wang W (2014) Recovery of rare earth elements from waste fluorescent phosphors: $\mathrm{Na}_{2} \mathrm{O}_{2}$ molten salt decomposition. J Mater Cycles Waste Manag 16(4):635-641

14. Zhang X, Xie Y, Lin X, Li H, Cao H (2013) An overview on the processes and technologies for recycling cathodic active materials from spent lithium-ion batteries. J Mater Cycles Waste Manage 15(4):420-430

15. Zhang P, Ma Y, Xie F (2013) Impacts of ultrasound on selective leaching recovery of heavy metals from metal-containing waste sludge. J Mater Cycles Waste Manag 15(4):530-538

16. Pinto ISS, Soares HMVM (2013) Recovery of molybdates from an alkaline leachate of spent hydrodesulphurisation catalyst proposal of a nearly-closed process. J Cleaner Prod 52:481-487
17. Alonso F, Ramirez S, Ancheyta J, Mavil M (2008) Alternatives for recovering of metals from heavy hydrocarbons spent hydrotreating catalysts a case of study. Rev Int Contamin Amb 24(2):55-69

18. Zeng L, Cheng CY (2009) A literature review of the recovery of molybdenum and vanadium from spent hydrodesulphurisation catalysts Part I: metallurgical processes. Hydrometallurgy 98(1-2):1-9

19. Gaballah I, Djona M, Mugica JC, Solozobal R (1994) Valuable metals recovery from spent catalysts by selective chlorination. Resour Conserv Recycl 10(1-2):87-96

20. Li J, Liang C, Ma C (2015) Bioleaching of gold from waste printed circuit boards by Chromobacterium violaceum. J Mater Cycles Waste Manag 17(3):529-539

21. Vemic M, Bordas F, Comte S, Guibaud G, Lens PNL, van Hullebusch ED (2016) Recovery of molybdenum, nickel and cobalt by precipitation from the acidic leachate of a mineral sludge. Environ Technol 37(17):2231-2242

22. Chen T, Lei C, Yan B, Xiao XM (2014) Metal recovery from the copper sulfide tailing with leaching and fractional precipitation technology. Hydrometallurgy 147:178-182

23. Fernandes A, Afonso JC, Dutra AJB (2013) Separation of nickel(II), cobalt(II) and lanthanides from spent Ni-MH batteries by hydrochloric acid leaching, solvent extraction and precipitation. Hydrometallurgy 133:37-43

24. Cibati A, Cheng KY, Morris C, Ginige MP, Sahinkaya E, Pagnanelli F, Kaksonen AH (2013) Selective precipitation of metals from synthetic spent refinery catalyst leach liquor with biogenic $\mathrm{H}_{2} \mathrm{~S}$ produced in a lactate-fed anaerobic baffled reactor. Hydrometallurgy 139:154-161

25. Zhang H, He P-J, Shao L-M, Li X-J (2008) Leaching behavior of heavy metals from municipal solid waste incineration bottom ash and its geochemical modeling. J Mater Cycles Waste Manag 10(1):7-13

26. Fernandes A, Afonso JC, Dutra AJB (2012) Hydrometallurgical route to recover nickel, cobalt and cadmium from spent $\mathrm{Ni}-\mathrm{Cd}$ batteries. J Power Sources 220:286-291

27. Pinto ISS, Sadeghi SM, Izatt NE, Soares H (2015) Recovery of metals from an acid leachate of spent hydrodesulphurization catalyst using molecular recognition technology. Chem Eng Sci 138:353-362

28. Zawierucha I, Kozlowski C, Malina G (2013) Removal of toxic metal ions from landfill leachate by complementary sorption and transport across polymer inclusion membranes. Waste Manag (Oxford) 33(10):2129-2136

29. Soukand U, Kangsepp P, Kakum R, Tenno T, Mathiasson L, Hogland W (2010) Selection of adsorbents for treatment of leachate: batch studies of simultaneous adsorption of heavy metals. J Mater Cycles Waste Manag 12(1):57-65

30. Habashi F (1997) Handbook of extractive metallurgy. Wiley$\mathrm{VCH}$, Weinheim

31. Niemela M, Pitkaaho S, Ojala S, Keiski RL, Peramaki P (2012) Microwave-assisted aqua regia digestion for determining platinum, palladium, rhodium and lead in catalyst materials. Microchem J 101:75-79

32. Portela L, Grange P, Delmon B (1995) XPS and NO adsorption studies on alumina-supported Co-Mo catalysts sulfided by different procedures. J Catal 156(2):243-254

33. Valverde IM Jr, Paulino JF, Afonso JC (2008) Hydrometallurgical route to recover molybdenum, nickel, cobalt and aluminum from spent hydrotreating catalysts in sulphuric acid medium. $\mathbf{J}$ Hazard Mater 160(2-3):310-317

34. Erust C, Akcil A, Bedelova Z, Anarbekov K, Baikonurova A, Tuncuk A (2016) Recovery of vanadium from spent catalysts of sulfuric acid plant by using inorganic and organic acids: Laboratory and semi-pilot tests. Waste Manag (Oxford) 49:455-461 
35. Nguyen TH, Lee MS (2015) Development of a hydrometallurgical process for the recovery of calcium molybdate and cobalt oxalate powders from spent hydrodesulphurization (HDS) catalyst. J Cleaner Prod 90:388-396

36. Aydogan S, Aras A, Ucar G, Erdemoglu M (2007) Dissolution kinetics of galena in acetic acid solutions with hydrogen peroxide. Hydrometallurgy 89(3-4):189-195

37. Tanda BC, Eksteen JJ, Oraby EA (2018) Kinetics of chalcocite leaching in oxygenated alkaline glycine solutions. Hydrometallurgy 178:264-273

38. Chander S (1982) Atmospheric-pressure leaching of nickeliferous laterites in acidic media. Trans Indian Inst Met 35(4):366-371

39. Terekhov DS, Emmanuel NV (2013) Direct extraction of nickel and iron from laterite ores using the carbonyl process. Miner Eng $54: 124-130$

40. Schortmann WE, DeSesa MA (1958) Kinetics of the dissolution of uranium dioxide in carbonate-bicarbonate solutions. In:; National Lead Co., Inc. Raw Materials Development Lab., Winchester, Mass. page(s): 17, Medium: X

41. Beverly RG, Charles WD (1958) Pilot Plant alkaline leaching of uranium ores. US Government Printing Office

42. Sohn HY, Wadsworth ME (1979) Rate processes of extractive metallurgy. Springer US, New York

43. Aly MM, Hamza MF (2013) A Review: studies on uranium removal using different techniques. Overview J Dispers Sci Technol 34(2):182-213
44. Merritt RC (1971) The Extractive Metallurgy of Uranium. Colorado School of Mines Research Institute, [Golden

45. Ferella F, Ognyanova A, De Michelis I, Taglieri G, Veglio F (2011) Extraction of metals from spent hydrotreating catalysts: Physico-mechanical pre-treatments and leaching stage. J Hazard Mater 192(1):176-185

46. Svehla G (1996) Vogel's qualitative inorganic analysis. Addison Wesley Longman Ltd, Harlow

47. Lewis AE (2010) Review of metal sulphide precipitation. Hydrometallurgy 104(2):222-234

48. Luther GW, Rickard DT, Theberge S, Olroyd A (1996) Determination of metal (bi)sulfide stability constants of $\mathrm{Mn}^{2+}, \mathrm{Fe}^{2+}$, $\mathrm{Co}^{2+}, \mathrm{Ni}^{2+}, \mathrm{Cu}^{2+}$, and $\mathrm{Zn}^{2+}$ by voltammetric methods. Environ Sci Technol 30(2):671-679

49. Bhattacharyya D, Jumawan AB, Grieves RB (1979) Separation of toxic heavy metals by sulfide precipitation. Sep Sci Technol 14(5):441-452

50. Shapiro L (1975) Rapid analysis of silicate, carbonate, and phosphate rocks. In: U.S. Geol. Surv. Bull., Vol. 76, pIII, Report Number 1401, pp. 88

51. Baes CF Jr, Mesmer RE (1976) Hydrolysis of cations. Wiley, New York 